\title{
Trauma in Primary Teeth at a Specialized Service Center: Retrospective Cohort
}

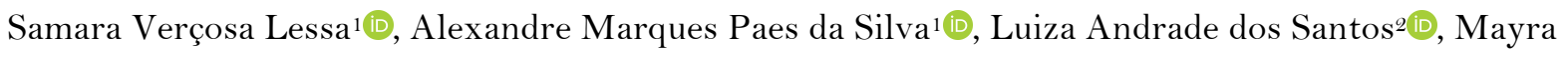 \\ Stambovsky Vieira ${ }^{3}$, Luciane Monte Alto de Seabra ${ }^{4}$, Dennis de Carvalho Ferreira ${ }^{3,5} \mathbb{0}$
}

\begin{abstract}
${ }^{1}$ Post-Graduation Department, School of Dentistry, Estácio de Sá University, Rio de Janeiro, RJ, Brazil. ${ }^{2}$ School of Dentistry, Estácio de Sá University, Rio de Janeiro, RJ, Brazil.

${ }^{3}$ Post-Graduation Department, School of Dentistry, Veiga de Almeida University, Rio de Janeiro, RJ, Brazil. ${ }^{4}$ Pediatric Dentistry Department, School of Dentistry, Estácio de Sá University, Rio de Janeiro, RJ, Brazil. ${ }^{5}$ Microbiology Department, School of Dentistry, Estácio de Sá University, Rio de Janeiro, RJ, Brazil.
\end{abstract}

Author to whom correspondence should be addressed: Alexandre Marques Paes da Silva, Rua General Ivan Raposo, 586/105, Barra da Tijuca, Rio de Janeiro, RJ, Brazil. 2262 1-040. Phone: +55 2197945-9393. E-mail: xandemps@gmail.com.

Academic Editors: Alessandro Leite Cavalcanti and Wilton Wilney Nascimento Padilha

Received: 23 July 2019 / Accepted: 27 February 2020 / Published: 24 March 2020

How to cite this article: Lessa SV, Silva AMP, Santos LA, Vieira MS, Seabra LMA, Ferreira DC. Trauma in primary teeth at a specialized service center: retrospective cohort. Pesqui Bras Odontopediatria Clín Integr. 2020; $20:$ e5092. https://doi.org/10.1590/pboci.2020.054

\begin{abstract}
Objective: To evaluate the factors associated with the occurrence of dental trauma in children up to six years of age and describe the results of clinical follow-up and possible sequelae. Material and Methods: A retrospective study was carried out with data collected from the dental records of 96 pediatric patients up to 6 years old with traumatized primary teeth who sought care from the. Pediatric Dental Trauma project of a private university in the city of Rio de Janeiro from July 2014 to July 2017, and who had clinical and radiographic follow-up for up to three months as of their initial visit. Results: 96 children $(58.3 \%$ boys and $41.7 \%$ girls) included who presented 166 traumatized primary teeth. Intrusion was the most observed type of trauma and in $45.8 \%$ of cases, the care occurred one-week post trauma. The maxillary central incisors were the most affected teeth $(97.6 \%)$. The prognosis of the dental elements with more than 3 months of follow-up was considered favorable, and $59.6 \%$ of the teeth did not present any clinical or radiological sequelae. Oral hygiene instruction and monitoring were the most common approaches. Conclusion: The prevalence of dental trauma in the present study was high and occurred mainly in domestic settings. The upper central incisors were the teeth that suffered the most injuries. The presence of patients at follow-up visits was an important factor for the positive result in most cases.
\end{abstract}

Keywords: Child; Dental Care; Primary Teeth; Dental Trauma; Intrusion. 


\section{Introduction}

Dental injuries in the primary dentition are emergencies involving the teeth, alveolar bone and adjacent soft tissues associated with the aesthetic, functional and psychic alterations of the child [1]. Data from the literature report that this trauma represents 15 to $35 \%$ of traumatic facial injuries, with the upper central incisors being the most commonly affected [2,3].

The classification of dental trauma in the primary dentition is divided into: dislocation lesions (concussions, subluxation, lateral luxation, intrusion, extrusion, avulsion); and alveolar bone fractures and bone-alveolar fractures. The lesions are usually subjective requiring detailed clinical and radiographic examination, since the severity of the lesion may be masked $[1,3,4]$.

The prognosis of dental trauma is largely associated with adequate management at the trauma site, requiring the knowledge of those responsible to differentiate between the type of trauma and the conduct of choice [5]. Sequelae accompanied by signs and symptoms may arise soon after traumatic lesions in primary teeth and acute pulpal pathologies are one of the most frequent complications associated with almost all types of dental trauma [6].

The negative impact generated by dental trauma on children's quality of life becomes of great relevance. Data collection to assess dental trauma, the profile of these patients, the factors associated with their occurrence, as well as their sequelae, should be studied so that they become instruments for the maintenance, prevention and appropriate treatment. Thus, the objective of this study was to describe the profile of dental trauma in pediatric patients through a retrospective cohort of up to three months or more who had clinical and radiographic follow-up, in addition to describing the main associated factors, as well as some partner aspects from a university clinic in Rio de Janeiro, Brazil.

\section{Material and Methods}

\section{Study Design and Sample}

A retrospective cohort study, based on data from the clinical records of patients attending the Pediatric Clinic of a private university in the State of Rio de Janeiro, Brazil, with a sample allocated by demand, composed of patients who suffered dental trauma in the primary dentition, with aged up to six years and had clinical and radiographic follow-up for up to three months or more.

\section{Data Collection}

Data collection was carried out from July 2014 to July 2017 during 3 month (july to september 2017) by two researchers previously trained. The variables collected from the charts included in the present study described: age; sex; cause of trauma; place of occurrence; type of trauma; dental element involved; time elapsed until the first service; recent approach (traumas occurring up to 24 hours); late approach; type of clinical sequel; type of radiological sequelae.

Ethical Aspects

This research was previously submitted and approved by the Research Ethics Committee of Estácio de Sá (CAAE 55135016.6.0000.5284). 
Data Analysis

The results were tabulated in a database created in Microsoft Office Excel and the data were analyzed using the Statistical Package for Social Science (SPSS), version 21.0 (IBM, Armonk, NY, USA). Data analysis was performed using chi-square and Fisher's exact tests with significance level of $5 \%$ and for the analysis of continuous variables, the Mann-Whitney test was used.

\section{Results}

The dental trauma characterization can be observed in Table 1. The sample number of patients attended during the "Dental Trauma" project was 96 children, 56 (58.3\%) boys and 40 (41.7\%) girls. The age group comprised between two and three years of age was the most frequently involved, being 25 (26\%) boys and $18(18.7 \%)$ girls, respectively. It should be noted that in the six-year age group, only two (2.1\%) individuals presented dental trauma, both males.

Table 1. Characterization of dental trauma.

\begin{tabular}{|c|c|c|c|c|}
\hline \multirow{3}{*}{ Variables } & \multicolumn{2}{|c|}{ Gender } & \multirow[t]{2}{*}{ Total } & \multirow{3}{*}{ p-value } \\
\hline & Male & Female & & \\
\hline & $\mathrm{N}(\%)$ & N (\%) & $\mathrm{N}(\%)$ & \\
\hline Patients & $56(58.3)$ & $40(41.7)$ & $96(100.0)$ & - \\
\hline Age - Months (Mean and SD) & $37.16( \pm 13.97)$ & $2.9( \pm 1.3)$ & $37.42( \pm 14.31)$ & $0.805^{* *}$ \\
\hline \multicolumn{5}{|l|}{ Age (Years) } \\
\hline 1 F 2 Years & $3(3.1)$ & $10(10.4)$ & $13(13.5)$ & - \\
\hline 2 F 3 Years & $22(22.9)$ & $8(8.3)$ & $30(31.2)$ & $0.044^{*}$ \\
\hline 3 - 4 Years & $12(12.5)$ & $8(8.3)$ & $20(20.8)$ & - \\
\hline $4+5$ Years & $12(12.5)$ & $8(8.3)$ & $20(20.8)$ & - \\
\hline 5 - 6 Years & $4(4.2)$ & $6(6.3)$ & $10(10.4)$ & - \\
\hline $6 卜<7$ Years & $3(3.1)$ & - & $3(3.1)$ & - \\
\hline \multicolumn{5}{|l|}{ Cause } \\
\hline Falls & $51(53.1)$ & $37(38.5)$ & $88(91.7)$ & $1.00^{\#}$ \\
\hline Traffic Accidents & - & $1(1.0)$ & $1(1.0)$ & \\
\hline Practice of Sports & $2(2.1)$ & $2(2.1)$ & $4(4.2)$ & \\
\hline No Information & $3(3.1)$ & - & $3(3.1)$ & \\
\hline \multicolumn{5}{|l|}{ Location of Occurence } \\
\hline House & $28(29.2)$ & $24(25.0)$ & $52(54.2)$ & $0.33^{*}$ \\
\hline School & $12(12.5)$ & $7(7.3)$ & $19(19.8)$ & $0.79^{\#}$ \\
\hline Square & $10(10.4)$ & $5(5.2)$ & $15(15.6)$ & \\
\hline Automobile & - & $1(1.0)$ & $1(1.0)$ & \\
\hline No Information & $6(6.3)$ & $3(3.1)$ & $9(9.4)$ & \\
\hline Traumatized Primary Teeth & $98(59.0)$ & $68(41.0)$ & $166(100.0)$ & \\
\hline \multicolumn{5}{|l|}{ Type of Trauma } \\
\hline Crown Fracture & $13(7.8)$ & $10(6.0)$ & $23(13.8)$ & - \\
\hline Crown Fracture with Pulp Exposure & $2(1.2)$ & $1(0.6)$ & $3(1.8)$ & - \\
\hline Crown and Root Fracture & $2(1.2)$ & $5(3.0)$ & $7(4.2)$ & - \\
\hline Root Fracture & - & - & - & - \\
\hline Concussion & $2(1.2)$ & $4(2.4)$ & $6(3.6)$ & - \\
\hline Subluxation & $10(6.0)$ & $8(4.8)$ & $18(10.8)$ & - \\
\hline Lateral Dislocation & $18(10.8)$ & $12(7.2)$ & $30(18.1)$ & $0.90^{*}$ \\
\hline Intrusion & $28(16.9)$ & $10(6.0)$ & $38(22.9)$ & $0.03 *$ \\
\hline Extrusion & $1(0.6)$ & $2(1.2)$ & $3(1.8)$ & - \\
\hline
\end{tabular}




\begin{tabular}{|c|c|c|c|c|}
\hline Avulsion & $12(7.2)$ & $10(6.0)$ & $22(13.2)$ & - \\
\hline No Information & $10(6.0)$ & $6(3.6)$ & $16(9.6)$ & - \\
\hline \multicolumn{5}{|l|}{ Dental Element Involved } \\
\hline Upper Right Central Incisor & $43(25.9)$ & $27(16.3)$ & $70(42.2)$ & $0.59^{*}$ \\
\hline Upper Right Lateral Incisor & $5(3.01)$ & $3(1.8)$ & $8(4.81)$ & - \\
\hline Left Upper Central Incisor & $39(23.5)$ & $32(19.3)$ & $71(42.8)$ & $0.35^{*}$ \\
\hline Upper Left Lateral Incisor & $7(4.2)$ & $5(3.6)$ & $12(7.8)$ & - \\
\hline Upper Left Canine & $2(1.2)$ & - & $2(1.2)$ & - \\
\hline Second Upper Left Molar & $1(0.6)$ & - & $1(0.6)$ & - \\
\hline Right Lower Incisor & $1(0.6)$ & - & $1(0.6)$ & - \\
\hline Right Lower Lateral Incisor & - & $1(0.60 \%)$ & $1(0.6)$ & - \\
\hline \multicolumn{5}{|l|}{ Time Elapsed Until the First Service } \\
\hline Up to 24 hours & $20(12.1)$ & $12(7.2)$ & $32(19.3)$ & $0.65 *$ \\
\hline 3 Days & $17(10.2)$ & $13(7.8)$ & $30(18.1)$ & $0.77 *$ \\
\hline 1 Week & $40(24.1)$ & $36(21.7)$ & $76(45.8)$ & $0.12^{*}$ \\
\hline 1 Month & $11(6.6)$ & $5(3.0)$ & $16(9.6)$ & - \\
\hline More than 1 Month & $6(4.8)$ & $2(1.2)$ & $8(4.8)$ & - \\
\hline No Information & $4(2.4)$ & - & $4(2.4)$ & - \\
\hline
\end{tabular}

*Chi-square test; **Mann-Whitney test; \#Fisher's exact test.

Regarding the type of trauma suffered, dislocation lesions appeared as the main type of trauma, followed by coronary fractures. When the type of dental trauma and the number of teeth involved were related, intrusion was observed as the most common type of trauma (22.9\%), followed by lateral dislocation (18.1\%) and crown fracture (13.8\%). Extrusion and crown fracture with exposure were present in only three (1.8\%) patients each. In all trauma modalities described, only crown and root fracture, concussion and extrusion occurred in a greater number of affected females, five (3.0\%), four $(2.4 \%)$ and two $(1.2 \%)$, respectively.

Regarding the causes of recorded injuries, the fall in height itself occurred more frequently (91.7\%), with the upper incisors being the most involved in this type of accident, especially the upper central incisors.

When analyzing the time elapsed between the accident and the demand for dental care, it was observed that most of the participants sought care after seven days, followed by the consequence after three days of the trauma suffered.

After seeking care, the immediate approaches were varied, with emphasis on the mode of follow-up of the case and oral hygiene instructions (13.3\%), followed by exodontia and endodontic treatment, $4.2 \%$ and $1.2 \%$, respectively. As a late approach in two $(1.2 \%)$ of the occasions, the splint was chosen as a treatment form and the endodontics appeared in 18 occasions, corresponding to $10.8 \%$ of the total (Table 2 ).

Table 2. Description of the approaches used and possible sequelae.

\begin{tabular}{|c|c|c|}
\hline Variables & $\mathbf{N}(\%)$ & p-value \\
\hline \multicolumn{3}{|c|}{ Recent Approach (Traumas Occurring up to 24 Hours) } \\
\hline Exodontia & $7(4.2)$ & - \\
\hline Endodontics & $2(1.2)$ & - \\
\hline Tracking + IHO & $22(13.3)$ & $0.70^{\#}$ \\
\hline Restoration & - & - \\
\hline Splinting & $1(0.6)$ & - \\
\hline Total & $32(19.3)$ & \\
\hline \multicolumn{3}{|l|}{ Late Approach } \\
\hline Exodontia & $6(3.6)$ & - \\
\hline Endodontics & $18(10.8)$ & - \\
\hline
\end{tabular}




$\begin{array}{lcc}\text { Tracking + IHO } & 104(62.7) & 0.53^{*} \\ \text { Restoration } & 4(2.4) & - \\ \text { Splinting } & 134(80.72) & - \\ \text { Total } & & - \\ \text { Type of Clinical Sequelae } & 88(53.0) & -21^{*} \\ \text { None } & 63(37.9) & - \\ \text { Mobility } & 15(9.1) & 166(100.0) \\ \text { Crown Discoloration } & 99(59.6) & - \\ \text { Total } & 5(3.0) & - \\ \text { Radiological Sequelae } & 8(4.8) & - \\ \text { No Sequelae } & 8(4.8) & - \\ \text { Periapical Lesion } & 8(4.8) & - \\ \text { Internal Resorption } & 38(22.9) & - \\ \text { External Resorption } & 166(100.0) & \end{array}$

Among the sequelae observed in the traumatized teeth included in the study were: periapical lesion $(3.0 \%)$, internal resorption $(4.8 \%)$, external resorption $(4.8 \%)$ and calcification of the pulp (4.8\%). The majority of the elements involved $(59.6 \%)$ did not present any type of radiological sequelae. Regarding the clinical sequels, the main registered was tooth mobility, representing $37.9 \%$ of the teeth, most of which remained without any sequelae $(53.0 \%)$.

In Figure 1 we observed the descriptive analysis of the total sample of traumatized teeth $(\mathrm{n}=166)$ included in the present study, distributing the type of trauma, treatment of choice and prognosis with followup time. Initially, 40 dental elements from the total sampling performed only a single visit and did not return to follow-up (14 primary teeth had a favorable prognosis, ten unfavorable teeth, and 16 individuals did not have information on the dental chart referring to the type of injury that was affected).

Thus, 126 teeth were followed between seven and 30/31 days, and it was observed that in 123 dental elements, the prognosis was favorable, where the treatment of choice was the follow-up associated with oral hygiene instruction (OHI), of this total, 24 teeth had no follow-up until the eruption of the successor tooth. Only three elements had as procedure: an exodontia and two endodontics, and its prognosis is considered unfavorable.

In the period of greater than one month up to three months, 100 dental elements followed their follow-up, totalizing an unfavorable prognosis of 21 teeth, 18 of which were exodontia and three endodontic treatments, and 79 followed with a favorable prognosis with 75 teeth performing the follow-up visit and four restorations definitive. In this period of preservation, a total of 30 primary teeth were discharged.

And in the last period of follow-up (more than three months), 70 teeth were followed, only two elements suffered exodontia, and 68 followed its accompaniment until the eruption of its successor. The monitoring appointments of the traumatized teeth were important to obtain a favorable prognosis, being noticed the commitment of the great majority of the patients during the returns, since of the total, 100 dental elements maintained their favorable prognosis during the periods of follow-up and 68 elements were prosecuted without clinical or radiographic sequelae for more than three months of follow-up (Figure 1). 


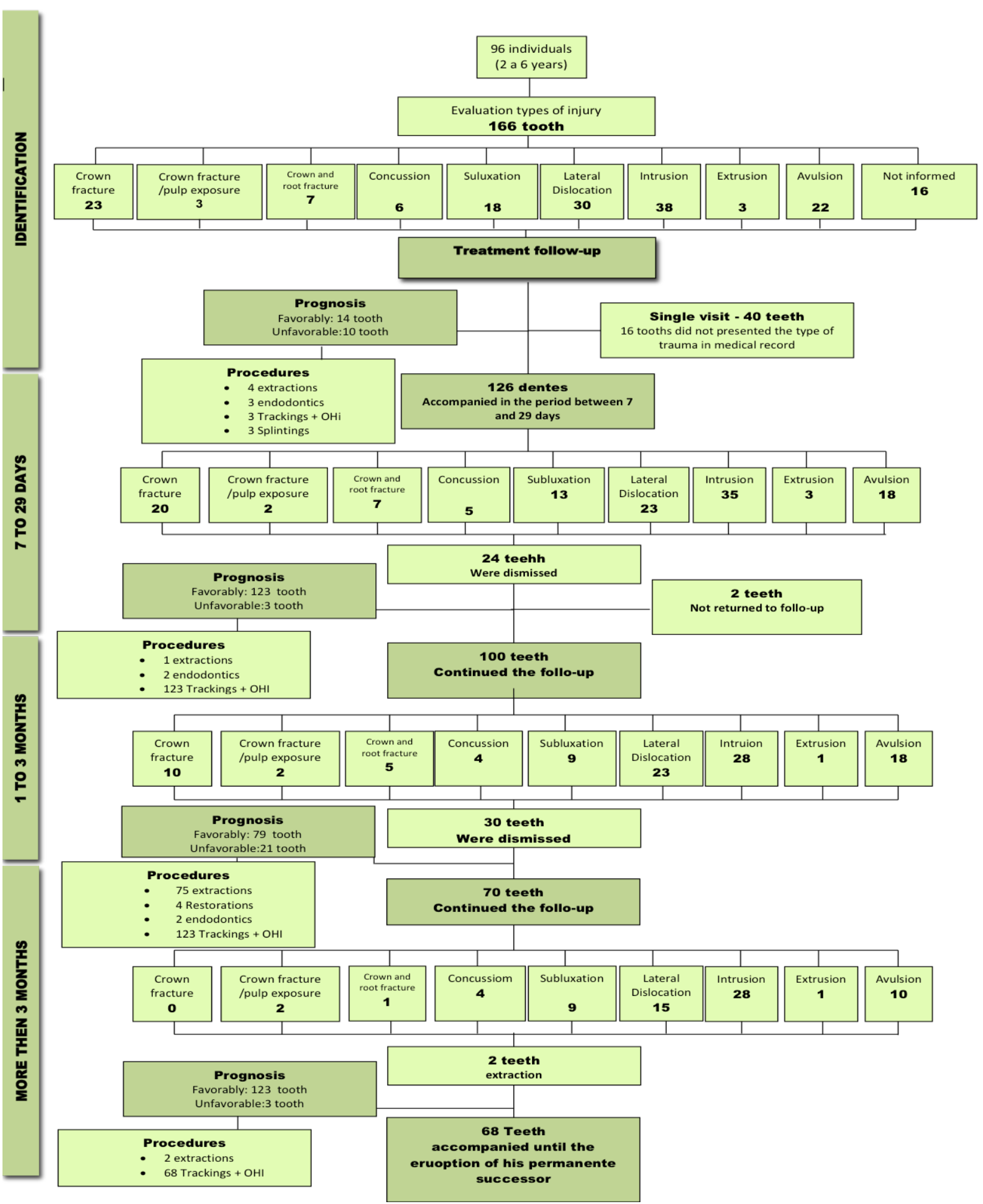

Figure 1. Distribution of the sample of traumatic dental elements and its outcome by follow-up time.

\section{Discussion}

The trauma in the primary dentition is an emergency that requires of the dentist, scrutiny of the traumatized tooth and all adjacent structures. In this study, the sample had 166 primary elements, injured between August 2014 and July 2017, followed by months after dental trauma. Longitudinal studies presented samples with 191 and 126 primary traumatized teeth, respectively, where the information was collected in five years $[7,8]$. 
The majority of studies evaluating dislocation lesions in the primary dentition are more frequent in male patients, being in agreement with the results found in our study (59.4\%) [9-12]. There are published works, where there was no difference of genres [13,14].

Several studies have shown that children are more prone to traumatic injuries in the age range of two to three years because they are learning to walk and become more independent [10-17]. Our results are in line with the literature, showing that despite any phase between zero and six years, the age most affected by dental trauma is two years $-13.5 \%$; three years $-31.2 \%$. The fall of height itself is the main cause of dental trauma in the primary dentition, independent of age, followed by sports and traffic accidents [1,18-20]. As seen in our results, where 88 of the 96 included patients suffered a fall from their own height.

Subluxation is the most frequently reported dental trauma in most of the published studies, being of a lower magnitude and the search for dental care, often neglected by those responsible [10,12,13,15-17,21]. In this study, intrusion was the most frequent dental trauma in $38(22.8 \%)$ injured teeth, followed by lateral dislocation with $30(18.1 \%)$ and subluxation as the third most frequently found $18(10.8 \%)$. In the association between trauma and gender, the male showed greater availability for intrusive dislocation. This can be explained by the fact that boys are more prone to risk situations, such as playing sports [2].

The results of this study corroborate those published in the literature, where the incisors appear as the teeth most frequently affected by dental injuries, in both dentitions. This fact can be justified by the location and projection in the dental arch, the upper central incisors being more prone to these injuries [10,12-17].

It is known that regardless of the cause of the traumatic lesions, the time elapsed between dental trauma and care will directly influence the prognosis of the injured element $[10,11,13,14,16,17,19,22,23]$. This study showed that the search for primary care was varied, with most seeking care one week after the trauma. According to other authors, this delay can be justified by limiting the population's awareness of the consequences of trauma on the child's life, as well as the difficult access to dental services [1,2].

Due to the vast number of classification systems for these traumas, choosing the most appropriate treatment becomes a major challenge. Despite the existence of protocols to be followed, they are often neglected by practitioners in some developing countries. Thereby, in 2009, a protocol was proposed where initial conducts are essential and should be respected: Clinical examination evaluating adjacent teeth and tissues, presence of possible foreign bodies in the oral cavity, radiographic examination to evaluate the possible presence of fracture and its extension, and stage of root development, and patient orientation on the best approach to be followed in the face of the trauma. This protocol was adopted in the present study in $69.87 \%$ of the teeth involved [24].

Exodontia is a treatment option, but should only be considered, after a thorough clinical and radiographic evaluation [25]. The proportion of teeth extracted in this study contrasts with the results of the study [12], where extraction was the most used modality, however, the age range of the sample comprised individuals between zero and 15 years old, that is, individuals who had the mixed dentition, or even the permanent. It is likely that this can be justified by the fact that our project offers emergency and control treatment. The rehabilitation is carried out in a postgraduate course outside the university due to the low age of the patients.

Restorations may be a viable treatment option in teeth with less complex fractures and no pulp involvement, and it is important that the involved teeth be periodically and clinically monitored [24]. Endodontic treatment was adopted at a very low frequency, $3.0 \%$, in contrast to other studies where $23.9 \%$ of the teeth studied underwent this treatment modality [26]. 
Some radiological sequelae such as root resorption can be observed in cases of dental trauma (9.6\%), with internal resorption $4.81 \%$ and external resorption $4.81 \%$ as well as in other studies [27]. The presence of clinical sequelae is significantly related to the severity of the lesion, which does not occur with the radiological sequel [28], justifying our results, where the number of traumatized teeth with clinical sequelae (47\%) was superior to radiological ones $(41.6 \%)$. This can be explained by another study with patients of similar ages to the present study, showing that the degree of maturation of the roots of primary teeth at the moment of the lesion may be associated with possible sequels presented [29]. Such a finding can be explained by the fact that children with less age have a more open root apex, consequently, a greater vascularization in the place, improving the response of the host to the trauma [30].

The color change occurred in $9.08 \%$ of the teeth analyzed in this study. It is an important factor to be observed in traumatized teeth, but it is not sufficient to diagnose pulpal necrosis and should be monitored radiographically for at least one year after the accident. After this period, without perirradicular lesion formation, the tooth responding to the tests of pulp vitality and without increased mobility, we can say that the tooth is re-vascularized and with vital pulp [31].

Monitoring appointments in cases of dental trauma in primary teeth are extremely important, this short or long-term follow-up evaluates the healing, oral hygiene level and the presence of sequelae [32]. The need for longer monitoring is due to the late emergence of sequelae or the failure of treatments in the immediate approach $[6,12]$. In this study, parents were advised on the importance of periodic return visits and 126 primary traumatized teeth were initially prosecuted for up to one month. A study conducted in Denmark showed that the number of consultations required for evaluation of traumatized teeth can vary from three to 17 , but over time there is a loss of patients in the return visits. In the abovementioned study, of the 287 analyzed teeth, after 36 months of follow-up, there was a loss of follow-up in $26.8 \%$ of cases [27,33].

From the perspective of the present study, clinical monitoring for a longer period of time is necessary, mainly in cases of more severe dental trauma, due to its possible sequelae. As a limitation, one can consider is the challenge of clinical follow-up for longer period of time, since most patients did not present clinical changes.

As this is a public health problem, the dental surgeon plays a fundamental role in emergency care in order to ensure a better prognosis for the dental elements involved, promoting health, esthetics and a healthy psychic state for the patient suffering from dental trauma. Thus, knowing that we cannot extrapolate the results to scientific evidence with large sample numbers, the present study can serve as a basis for future research with a greater number of cases and post-trauma follow-up.

\section{Conclusion}

The most observed type of trauma was intrusion, with the dental elements most involved in dental trauma involving the primary dentition, the upper incisors, especially the central incisors, the age group most susceptible to these accidents being, between two and three years of age. The search for a dental care, which according to the data collected in this study, shows that this is still a great challenge to overcome, since most parents and/or legal guardians seek care around one week after the accident.

\section{Authors' Contributions}

SVL (D) 0000-0002-0544-4095 Conceptualization, Methodology, Investigation, Formal Analysis, Validation, Writing - Original Draft Preparation and Writing - Review and Editing. 


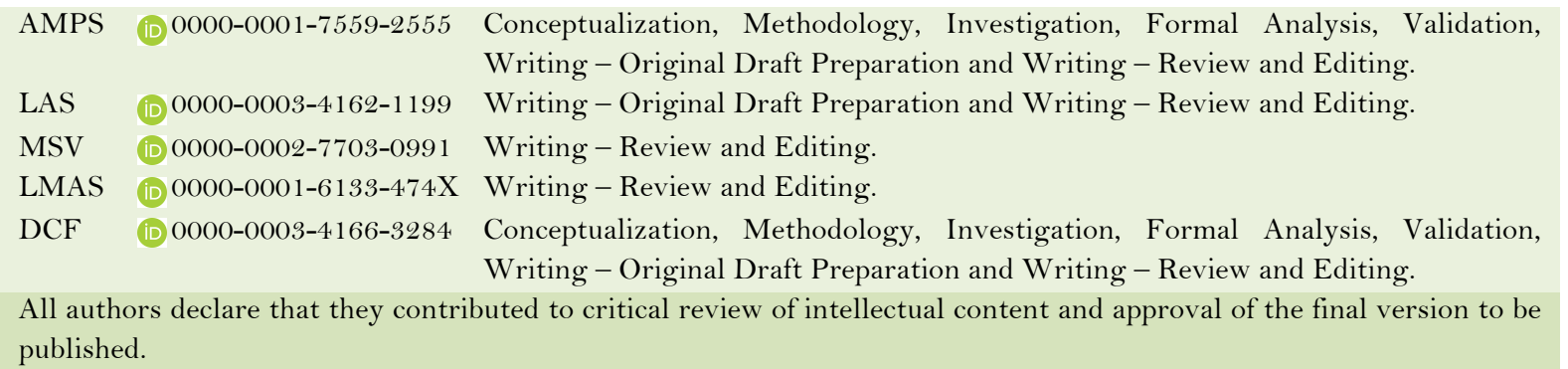

\section{Financial Support}

None.

\section{Conflict of Interest}

The authors declare no conflicts of interest.

\section{References}

[1] Andersson L, Andreasen JO, Day F, Heithersay G, Trope M, Diangelis AJ, et al. International Association of Dental Traumatology. Guidelines for the Management of Traumatic Dental Injuries: 2. Avulsion of permanent teeth. Dent Traumatol 2012; 28(2):88-96. https://doi.org/10.1111/j.1600-9657.2012.01125.x

[2] Glendor U. Epidemiology of traumatic dental injuries - a 12 years review of the literature. Dent Traumatol 2008; 24(6):603-11. https://doi.org/10.1111/j.1600-9657.2008.00696.x

[3] Oskoui M, Coutinho F, Dykeman J, Jetté N, Pringsheim T. An update on the prevalence of cerebral palsy: a systematic review and meta-analysis. Dev Med Child Neurol 2013; 55(6):509-19. https://doi.org/10.1111/dmcn.12080

[4] Francisco SS, José Filho F, Pinheiro ET, Murrer RD, Soares AJ. Prevalence of traumatic dental injuries and associated factors among Brazilian schoolchildren. Oral Health Prev Dent 2013; 11(1):31-8. https://doi.org/10.3290/j.ohpd.a29373

[5] Al-Musawi A, Al-Sane M, Lars A. Smartphone app as an aid in the emergency management of avulsed teeth. Dent Traumatol 2017; 33(1):13-8. https://doi.org/10.1111/edt.12298

[6] Holan G, Cohenca N, Brin I, Sgan-Cohen H. An oral health promotion program for the prevention of complications following avulsion: the effect on knowledge of physical education teachers. Dental Traumatol 2006; 22(6):323-7. https://doi.org/10.1111/j.1600-9657.2005.00387.x

[7] Mendoza-Mendoza A, Iglesias-Linares A, Yañez-vico RM, Abalos-Labruzzi C. Prevalence and complications of trauma to the primary dentition in a subpopulation of Spanish children in southern Europe. Dent Traumatol 2015; 31(2):144-9. https://doi.org/10.1111/edt.12147

[8] Assunção LRS, Cunha RF, Ferelle A. Análise dos traumatismos e suas sequelas na dentição decídua: uma revisão da literatura. Pesqui Bras Odontopediatria Clín Integr 2007; 7(2):173-9. https://doi.org/10.4034/1519.0501.2007.0072.0012

[9] Fontenele M, Macedo M, Rebouças P, Silva PGB, Sousa DL, Sousa RBRA, et al. Sequelae in primary teeth after traumatic injury. Braz Dent Sci 2017; 20(2):70-5. https://doi.org/10.14295/bds.2017.v20i2.1350

[10] Mahmoodi B, Rahimi-Nedjat R, Weusmann J, Azaripour A, Walter C, Wilershausen B. Traumatic dental injuries in a university hospital: a four-year retrospective study. BMC Oral Health 2015; 15(1):139. https://doi.org/10.1186/s12903-015-0124-5

[11] Shqair A, Gomes GB, Oliveira A, Goettems ML, Romano AR, Schardozim LR, et al. Dental emergencies in a university pediatric dentistry clinic: a retrospective study. Braz Oral Res 2012; 26(1):50-6. http://dx.doi.org/10.1590/S1806-83242012000100009

[12] Muriithi HM, Masiga MA, Chindia ML. Dental injuries in 0-15 years old at the Kenyatta National Hospital, Nairobi. East Afr Med J 2005; 82(11): 592-7. https://doi.org/10.4314/eamj.v82i11.9415

[13] Naidu RS, Boodoo D, Percival T, Newton JT. Dental emergencies presenting to a university-based paediatric dentistry clinic in the West Indies. Int J Paediatr Dent 2005; 15(3):177-84. https://doi.org/10.1111/j.1365-263X.2005.00625.x

[14] Elkarmi RF, Hamdan MA, Rajab LD, Abu-Ghazaleh SB, Sonbol HN. Prevalence of traumatic dental injuries and associated factors among preschool children in Amman, Jordan. Dent Traumatol 2015; 31(6):487-92. https://doi.org/10.1111/edt.12183 
[15] Eyuboglu O, Yilmaz Y, Zehir C, Sahin H. A 6-year investigation into types of dental trauma treated in a paediatric dentistry clinic in Eastern Anatolia region, Turkey. Dent Traumatol 2009; 25(1):110-4. https://doi.org/10.1111/j.1600-9657.2008.00668.x

[16] Andreasen JO, Lauridsen E, Gerds TA, Ahrensburg SS. Dental trauma guide: a source of evidence-based treatment guidelines for dental trauma. Dent Traumatol 2012; 28(5):345-50. https://doi.org/10.1111/j.1600-9657.2011.01059_1.x

[17] Norton E, O'Connell AC. Traumatic dental injuries and their association with malocclusion in the primary dentition of Irish children. Dent Traumatol 2012; 28(1):81-6. https://doi.org/10.1111/j.1600-9657.2011.01032.x

[18] Colak I, Markovic D, Petrovic B, Peric T, Milenkovic A. A retrospective study of intrusive injuries in primary dentition. Dent Traumatol 2009; 25(6):605-10. https://doi.org/10.1111/j.1600-9657.2009.00838.x

[19] Carvalho V, Jacomo DR, Campos V. Frequency of intrusive luxation in deciduous teeth and its effects. Dent Traumatol 2010; 26(4):304-7. https://doi.org/10.1111/j.1600-9657.2010.00893.x

[20] Antunes LA, Leão AT, Maia LC. The impact of dental trauma on quality of life of children and adolescents: a critical review and measurement instruments. Cien Saúde Colet 2012; 17(12):3417-24. https://doi.org/10.1590/s1413-81232012001200026

[21] de Amorim LF, Estrela C, Costa LRS. Effects of traumatic dental injuries to primary teeth on permanent teeth - a clinical follow-up study. Dent Traumatol 2011; 27(2):117-21. https://doi.org/10.1111/j.1600-9657.2010.00959.x

[22] Andreasen JO, Andreasen FM, Andersson L. Textbook and Color Atlas of Traumatic Injuries of the Teeth. Oxford: Blackwell Munksgaard; 2007.

[23] Lenzi R, Trope M. Revitalization procedures in two traumatized incisors with different biological outcomes. J Endod 2012; 38(3):41 1-4. https://doi.org/10.1016/j.joen.2011.12.003

[24] Macena MCB, Leite AC, Colares V, Vieira S, Neto LGC. Clinical protocol for assessment and management in dental trauma. RBPS 2009; 22(2):120-7.

[25] Brüllmann, D, Ralf KS, Bernd H. The treatment of anterior dental trauma. Dtsch Arztebl Int 2011; 108(34-35):56570. https://doi.org/10.3238/arztebl.2011.0565

[26] Aldrigui JM, Jabbar NS, Bonecker M, Braga MM, Wanderley MT. Trends and associated factors in prevalence of dental trauma in Latin America and Caribbean: a systematic review and meta-analysis. Community Dent Oral Epidemiol 2013; 42(1):30-42. https://doi.org/10.1111/cdoe.12053

[27] Trope M. Clinical management of the avulsed tooth: pre-sent strategies and future directions. Dent Traumatol 2002; 18(1):1-11. https://doi.org/10.1046/j.1600-4469.2001.00001.x

[28] Costa VP, Goettems ML, Baldissera EZ, Bertoldi AD, Torriani DD. Clinical and radiographic sequelae to primary teeth affected by dental trauma: a 9-year retrospective study. Braz Oral Res 2016; 30(1):1-9. https://doi.org/10.1590/1807-3107BOR-2016.vol30.0089

[29] Lopes TS, Santin GC, Marengoni LA, Crispim JB, Ceron LC, Fracasso MLC. Clinical and radiographic sequelae in primary teeth due to dental trauma. Pesqui Bras Odontopediatria Clín Integr 2019; 19:e4526. https://doi.org/10.4034/pboci.2019.191.95

[30] Borum MK, Andreasen JO. Sequelae of trauma to primary maxillary incisors. I. Complications in the primary dentition. Endod Dent Traumatol 1998; 14(1):31-44. https://doi.org/10.1111/j.1600-9657.1998.tbo0806.x

[31] Cardoso M, de Carvalho Rocha MJ. Traumatized primary teeth in children assisted at the Federal University of Santa Catarina, Brazil. Dent Traumatol 2002; 18(3):129-33. https://doi.org/10.1034/j.1600-9657.2002.00030.x

[32] Rodrigues I, Da Silva BS, Ceron LC, Lopes TS, Venante HS, Santin GC, et al. Treatment of side luxation in decided teeth - importance of preservation. Braz J Surg Clin Res 2017; 19(1):90-5.

[33] Qassem A, Goettems M, Torriani DD, Pappen FG. Radicular maturity level of primary teeth and its association with trauma sequelae. Dent Traumatol 2014; 30(3):227-31. https://doi.org/10.1111/edt.12072 